An explanation of the trend considered in this letter is to be expected from the investigation of a number of ststems of equilibrium of the type $\mathrm{FeSiO}_{3}-\mathrm{MgSiO}_{3}-\mathrm{NiSiO}_{3}$.

Institute of Plant Physiology,

PFR H. LUNDEgARDH.

Royal Agricultural College, Uppsala.

N Nature, 156, 207 (1945).

2 Nature, 155, $753(1945)$.

3 Min. Mag., 26, 283 (1943).

\title{
Initial Stages of the Explosion of Nitroglycerine
}

IT has been reported previously that when explosion is initiated in a thin conflned layer of nitroglycerine by impact or by condenser spark, the characteristic pattern of pressure marks impressed on the conflning surfaces indicates that the explosion proceeds through the layer in at least two successive stages ${ }^{1,2}$. This conclusion is supported by the disposition of the linminous effects observed when the explosion is initiated on a photographic plate or on a transparent anvil at the focus of a camera ${ }^{2}$.

A rotating drum camera ${ }^{3}$ has now been used to examine the initial stages of the explosion. The results obtained conflrm and amplify the conclusions arrived at from the earlier experiments $s^{1,2,4}$

A thin laver of nitroglycerine was confined between a circular brass disk $(3 \cdot 5 \mathrm{~cm}$. in diameter) and a transparent support. Initiation was effected by the passage of a condenser spark in a hole drilled at the centre of the disk, and the light from the explosion was photographed on a flim carried by the rotating drum. Close to the drum and at right angles to the direction of rotation a narrow slit was interposed. Thus a trace was obtained from which the velocity of propagation of the explosion at any point along the line of the slit (that is, the diameter of the nitroglycerine layer) could be calculated.

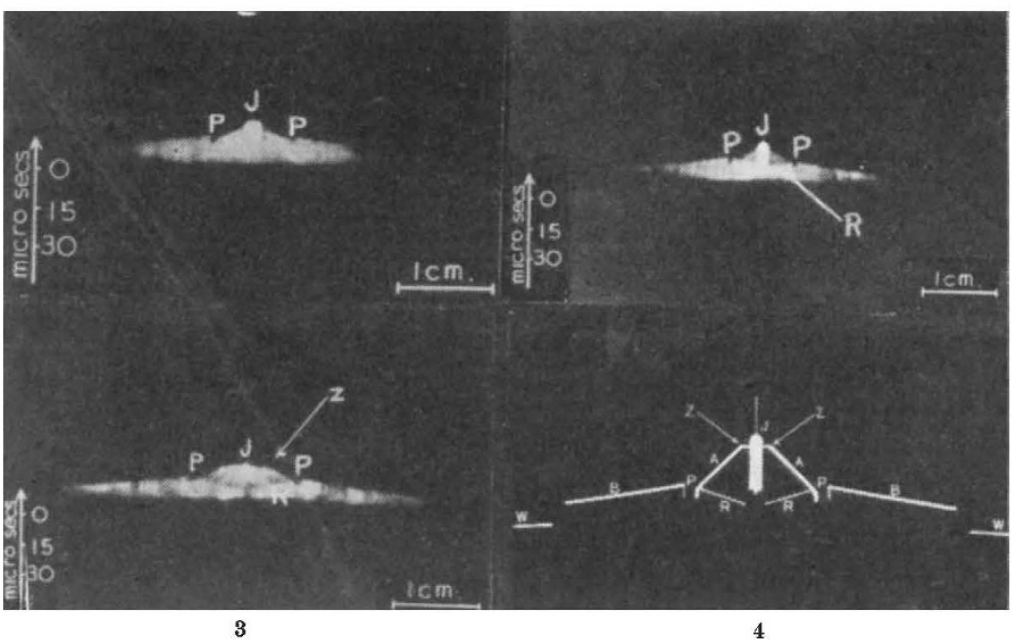

1 and 2. ROTATING-DRUM CAMERA TRACES OF EXPLOSIONS IN VERY THIN LAYERS OF NITROGLYCERINE. ARROW INDICATES DIRECTION OF MOTION OF FILM.

3. Trace OF EXPLOSION IN THICKER NITROgLYOERINE LAYER. 4. DiAgrammatio REPRESENTATION OF EXPLOSION TRACE.

$J$, point of initiation; $Z$, initial process of very high velocity ; $A$, propagation at $c .400$ metres/sec.; $P$, dark space ; $R$, 'retonation' wave ; $B$, propagation at $c .2,000$ metres/sec.; $R$, 'retonation' wave $; B$, propa
$W$, shock wave in atmosphere.

Figs. 1 and 2 are typical traces obtained with very thin layers (less than $0.01 \mathrm{~mm}$.) of nitroglycerine. The explosion is initiated at $J$ and propagates in both directions to $P$ at approximately $400(420 \pm 15$ per cent) metres/sec. At $P$ the velocity abruptly increases to approximately $2,000(1,800+c .5$ per cent) metres/sec and a retrograde process $R$ originates. $R$ is seen more clearly in Fig.

process $R$ originates. $R$ is seen more clearly in Fig. 2 . 2,000 metres/sec. process begins at a point in the nitroglycerine laver ahead of the 400 metres/sec. explosion front. With suitable extension ahead of the 400 metres/sec. explosion front. With suitable extension of the confined layer, the 2,000 metres/sec. process may be caused to ably corresponds to the 'low velocity' detonation characteristic of ably correspon

The initial stages of explosion in nitroglycerine under these conditions correspond quite closely, though on a much reduced scale, with the sequence of events characteristic of the setting up of detonawion in gaseous explosions. In particular, the abrupt change in velocity. tion in gaseous explosions. In particular, the abrupt change in velocity, the appearance of a 'retonation wave' $R$, and the 'auto-ignition' of
detonation ahead of the flame front are phenomena common to both detonation

When initiation is effected in a thicker layer (greater than $0.1 \mathrm{~mm}$.) the 400 metres/sec. process is preceded by a very fast process (exceedthe 400 metres/sec. process is preceded by a very fast process (exceeding 5,000 metres/sec.), cf. Fig. 3. After a short distance of propagation which the explosion proceeds exactly as in thinner layers. It is possible which the explosion proceeds exactiy as in thinner layers. 'Tt is possible that this initial stage of the explosion corresponds to the 'high velocity'
detonation ${ }^{5}$. Fig. 4 is an idealized diagram corresponding to an explosion trace obtained with a thick layer. rule.
Similar results have been obtained with nitroglycol and methyl itrate.

Council for Scientific and Industrial Research

R. G. VINES.

Section of Tribophysics, Chemistry Department, University of Melbourne.

Bowden, F. P., Eirich, F., Ferguson, A. E., and Yoffe, A., Coun. Sci. Ind. Res. (Aust.) Bull, 167 (1943).

P., Eirich, F., Mulcahy, M. F. R., Vines, R. G., and Y.. and Sraser. Res. (Aust.) Bull., 173 (1943).

Bone, W. A., and Fraser, R. P., Phil. Trans., A, 228, 197 (1929) Nature, 157, 105 (1946).

Noture, 157,105 (1946). Jones, F., Chariton, J. B., and Ratner, S. B., Proc. Roy. Soc., cf. Bone, W. A., and Townend, D. T. A., "Flame and Combustion in Gases" (Longmans, 1927). Egerton, A., and Gates, S. F., Proc. Roy. Soc., A, 114, 137 (1927). Bone, W. A., Fraser, R. P.'

Induced Dehydrochlorination of Substituted Ethanes

THE ease with which hydrogen chloride can be removed from imple aliphatic chloro-compounds by the action of alcoholic caustic alkali has been recognized for many years. It is also possible to split off hvdrogen chloride from these compounds by contact catalysis, or simply by pyrolysis, and there are many patents covering these pro-

During the study of such a thermal dehydrochlorination of ethylene dichloride, it has been found that the velocity of the reaction is remarkably dependent on the presence of small amounts of oxygen and/or chlorine, and on the purity of the ethylene dichloride. The accompanying table illustrates results obtained during dynamic ex periments in $11 \mathrm{~mm}$. I.D. Pyrex tubes heated uniformly for a length of $60 \mathrm{~cm}$., and with a uniformly for a length of $60 \mathrm{~cm}$. and with a how-rate of $38 \mathrm{gm}$. of ethylene dichloride per hour. Ethylene chlorhydrin, which forms an azeotrope ${ }^{1}$ with ethylene dichloride and which is normally present therein, inhibits the reaction, but can be removed by chemical treatment with, for ex

In all cases the sole reaction products are vinyl chloride and hydrogen chloride with a vinyl chloride and hydrogen chloride with a
trace of tarry matter. Packing the reactor with glass scrap to twice the original area with glass scrap to twice the original area (from 17 to 19 per cent conversion at $500^{\circ}$ ) for (from 17 to 19 per cent conversion at 500 ) for pure ethylene dichloride with no addition, but the oxygen- or chlorine-induced decomposition at 350 was almost completely inhibited under these conditions. The velocities of both induced reactions depended, for a constant contact time, on the reactor diameter increasing as this increased. Considerably smaller amounts of oxygen or chlorine than $\frac{1}{2}$ per cent by weight had an appreciable influence on the rate of the decomposition, the effect of even 0.01 per cent by weight of chlorine, for example, being easily detected. The oxygeninduced reaction was particularly sensitive to the presence of inhibitors and was entirely suppressed by the addition of less than $0 \cdot 1$ per cent by weight of various aliphatic alcohols and hydrocarbons; for ex ample, even 0.01 per cent of ethyl alcohol completely inhibited the reaction at $350^{\circ}$ Other halogens besides chlorine also induced the decomposition of ethylene dichloride : mole for mole, bromine was more effective than chlorine; but iodine, on the other hand, was almost without influence.

The effect of chlorine and oxygen in 'catalysing' the thermal decomposition of other chlorinated ethanes has also been studied. Remarkably enough, the effect of the added 'catalyst' depends very much on the structure of the chlorinated body. Thus, while the pyrolysis rates of pure 1,1,2-trichlor- and $1,1,2,2$-tetrachlor-ethanes were profoundly affected, the velocities of decomposition of purifled 1-chlor-, 1,1-dichlor-, 1,1,1,2-tetrachlorand pentachior-ethanes were almost uninfluenced. There is an obvious inverse correlation between these two groups and Markownikoft's

\begin{tabular}{|c|c|c|c|c|c|}
\hline \multirow[b]{2}{*}{$\begin{array}{c}\text { Temp. } \\
\text { in } \\
{ }^{\circ} \mathrm{C} .\end{array}$} & \multicolumn{5}{|c|}{ Percentage conversions } \\
\hline & $\begin{array}{l}\text { Fraction- } \\
\text { ated } \\
\left(\mathrm{CH}_{2} \mathrm{Cl}\right)_{2} ; \\
\text { no } \\
\text { addition }\end{array}$ & $\begin{array}{c}\text { Chem- } \\
\text { ically } \\
\text { purified } \\
\left(\mathrm{CH}_{2} \mathrm{Cl}\right)_{2} \\
\text {;o } \\
\text { addition }\end{array}$ & $\begin{array}{c}\text { Fraction- } \\
\text { ated } \\
\left(\mathrm{CH}_{2} \mathrm{Cl}\right)_{2} ; \\
+\frac{1}{2} \% \text { by } \\
\text { wt. of } \\
\text { oxygen }\end{array}$ & $\begin{array}{c}\text { Chem- } \\
\text { ically } \\
\text { purifted } \\
\left(\mathrm{CH}{ }_{2} \mathrm{CI}\right)_{2} ; \\
+\frac{1}{2} \% \text { by } \\
\text { wt. of } \\
\text { oxygen }\end{array}$ & $\begin{array}{c}\text { Chem- } \\
\text { ically } \\
\text { purifled } \\
\left(\mathrm{CH}_{2} \mathrm{Cl}\right)_{2} ; \\
+\quad \frac{1}{2} \% \text { by } \\
\text { wt. of } \\
\text { chlorine }\end{array}$ \\
\hline $\begin{array}{l}300 \\
350 \\
400 \\
450\end{array}$ & $\begin{array}{l}0 \\
0 \\
1 \\
3\end{array}$ & $\begin{array}{r}0 \\
0 \\
2 \\
12\end{array}$ & $\begin{array}{l}0 \\
0 \\
2 \\
-\end{array}$ & $\begin{array}{l}30 \\
60 \\
-\end{array}$ & $\begin{array}{l}30 \\
50 \\
65 \\
80\end{array}$ \\
\hline
\end{tabular}

